\title{
HEALTH-RELATED QUALITY OF LIFE ASSESSMENT USING SINGLE-INHALER DUAL VERSUS TRIPLE THERAPY IN CHRONIC OBSTRUCTIVE PULMONARY DISEASE PATIENTS
}

\section{TALATH FATIMA ${ }^{1}$, ANNIE FATIMA SADAF ${ }^{1}$, SYED AAMIR ALI ${ }^{1 *}$, JUNAID SIDDIQUI ${ }^{1}$, MIRZA MISBA ALI BAIG ${ }^{1}$, SYED MAHMOOD AHMED ${ }^{2}$, MEHRUQ FATIMA ${ }^{1}$}

${ }^{1}$ Department of Pharmacy Practice, Deccan School of Pharmacy, Hyderabad, Telangana, India. ${ }^{2}$ Department of Pulmonary Medicine, Owaisi Hospital and Research Center, Hyderabad, Telangana, India. Email: syed.aamir12@gmail.com

Received: 16 November 2019, Revised and Accepted: 01 January 2020

ABSTRACT

Objectives: The study compared triple therapy (inhaled corticosteroids/long-acting beta2-agonists [LABA]/long-acting muscarinic antagonists [LAMA]) versus dual therapy [LABA/LAMA] in improving lung function and health-related quality of life (HRQoL) of patients with chronic obstructive pulmonary disease (COPD).

Methods: This prospective and observational study compared 12 weeks of triple therapy (Formoterol $-6 \mathrm{mcg} /$ Ciclesonide $-200 \mathrm{mcg} /$ Tiotropium $-9 \mathrm{mcg}$ ) versus dual therapy (Formoterol $-6 \mathrm{mcg} /$ Tiotropium $-9 \mathrm{mcg}$ ) in COPD patients. The primary objective included HRQoL as measured by improvement (decrease) from baseline in St. George respiratory questionnaire (SGRQ) score and COPD assessment test (CAT) scores. Coprimary endpoint included the change from baseline in forced expiratory volume in 1 second (FEV1).

Results: After 12 weeks of treatment, triple therapy $(\mathrm{n}=30)$ and dual therapy (30), mean improvement (decrease) from baseline in SGRQ scores was -21.06 (95\% CI, -24.92--17.20) and -5.89571 (95\% CI, -7.71--4.07), respectively, and mean improvement (decrease) from baseline in CAT scores was $-2.83(95 \% \mathrm{CI},-3.73--1.94]$ and -1.8 (95\% CI, -2.25--1.35), respectively. The mean change from baseline in FEV1\% predicted was 3.09 (95\% CI, 2.18-4.00) and 1.69 (95\% CI, 1.43-1.97) for triple and dual therapy, respectively. For all the endpoints, the between-group mean differences were statistically significant $(\mathrm{p}<0.001)$.

Conclusion: Triple therapy (Formoterol $-6 \mathrm{mcg} /$ Ciclesonide $-200 \mathrm{mcg} /$ Tiotropium $-9 \mathrm{mcg}$ ) can provide improvements in lung function and quality of life over dual therapy (Formoterol $-6 \mathrm{mcg} /$ Tiotropium $-9 \mathrm{mcg}$ ) in patients with moderate to severe COPD. Future studies should focus on which drug combination of triple therapy is more effective and cost-effective than other possible triple therapy drug combinations.

Keywords: Chronic obstructive pulmonary disease, St. George respiratory questionnaire, Chronic obstructive pulmonary disease assessment test, Health-related quality of life, Lung function.

(C) 2020 The Authors. Published by Innovare Academic Sciences Pvt Ltd. This is an open access article under the CC BY license (http://creativecommons. org/licenses/by/4. 0/) DOI: http://dx.doi.org/10.22159/ajpcr.2020.v13i3.36392

\section{INTRODUCTION}

Chronic obstructive pulmonary disease (COPD) is a disorder of gradual lung function loss developing due to increasing breathing restrictions. Beta-agonists, corticosteroids, and muscarinic antagonists are a mainstay in the management of COPD. Based on the disease severity, recent GOLD guidelines recommend step-up therapy in the management of COPD [1,2]. To reap greater benefits, different combinations of long-acting beta2-agonists (LABA), inhaled corticosteroids (ICS), and long-acting muscarinic antagonists (LAMA) have been compared. These explorations proved triple therapy to be beneficial than dual therapy in terms of improvements in lung function, but variable results were obtained when the health-related quality of life (HRQoL) was concerned $[3,4]$.

Research has shown that COPD patients had deteriorated HRQoL $[5,6]$. In this regard, St. George respiratory questionnaire (SGRQ) and COPD assessment test (CAT) have been validated and used extensively in clinical trials [7-10]. The various patient-reported outcomes such as shortness of breath, inability to perform daily chores, mental stress, and enhanced hospitalizations can be better measured using HRQoL [11-14]. HRQoL measures such as SGRQ and CAT scores along with objective parameters like spirometry can provide exhaustive coverage of treatment response following drug therapy [15].

Thus, the objective of the present study was to evaluate the effectiveness of triple therapy (Formoterol $-6 \mathrm{mcg} /$ Ciclesonide $-200 \mathrm{mcg} /$ Tiotropium
- $9 \mathrm{mcg}$ ) versus dual therapy (Formoterol $-6 \mathrm{mcg} /$ Tiotropium $-9 \mathrm{mcg}$ ) in terms of lung function (forced expiratory volume in $1 \mathrm{~s}$ [FEV1] and forced vital capacity) and HRQoL (SGRQ and CAT scores).

\section{METHODS}

Study site

This prospective, non-interventional, open-labeled, and comparison study was performed in the outpatient and inpatient Pulmonology Department of Owaisi Hospital and Research Centre, a tertiary care hospital of South India, during the period of September 2018-February 2019. Due to a small number of patients, the study was designed to be conducted as a pilot study. A total of 60 moderate $(50 \% \leq \mathrm{FEV} 1<80 \%$ predicted) and severe $(30 \leq$ FEV1 $<50 \%$ predicted) COPD patients who were already on dual and triple therapy for the past 3 months were recruited and divided into two groups of 30 each. The recruitment was done based on convenience sampling. As this is a non-interventional study, specific visits are not mandated by the protocol. The following are the inclusion and exclusion criteria.

\section{Inclusion criteria}

The following criteria were included in the study.

- Patients of both genders, above 18 years and below 65 years

- Those patients who are prescribed with any one of the following drug therapies, i.e., either dual therapy or triple therapy

- Patients who are willing to give their informed consent to participate in the study

- Patients diagnosed with moderate or severe COPD. 
Exclusion criteria

The following criteria were excluded from the study.

- Patients who are not willing to participate in the study

- Pregnant woman are excluded

- Pediatrics patients are excluded

- Patients without moderate to severe COPD

- Patients with COPD but with a history of pleural effusion, congestive heart failure, coronary artery disease, malignancies, tuberculosis, and bronchiectasis.

\section{Ethical approval}

The study was approved by the Institutional Ethics Committee of Owaisi Hospital and Research Centre. All subjects gave informed consent to participate in the study and allowed the use of their personal data for research purposes.

\section{Data collection}

This study collected demographic, clinical, and HRQoL data of COPD patients. The study required a minimum of two visits during the 6-month survey. The data were collected from patients, patients treatment chart/ case sheets, lab reports, and from patient's attendees. Spirometry was performed at baseline and every month until 6 month period. Similarly, SGRQ and CAT forms were explained and completed from patients at baseline and every month until 6-month duration. For baseline and final values, a minimum of 3 months difference was considered. The patients were subdivided into responders and non-responders based on the minimal clinically important difference (MCID). MCID for SGRQ was $>4$ units improvement (decrease) from baseline for total score [16] and for CAT scores, MCID was $>2$ unit improvement (decrease) from baseline for total score $[8,9]$.

\section{Statistical analysis}

Continuous variables were presented as mean and standard deviation. Categorical variables were presented as numbers and percentages. Risk ratios and their associated $95 \%$ confidence intervals were used as effect measures for responders versus non-responders between triple and dual therapies. Similarly, mean difference and their associated 95\% confidence intervals were used as effect measures for presenting improvement from baseline values in FEV1, SGRQ and CAT scores between triple and dual therapies. $\mathrm{p}<0.05$ was deemed statistically significant. All statistical analysis was performed using Epi Info Software version 7.0 (CDC, Atlanta, Georgia, USA).

\section{RESULTS}

The present study divided 60 patients into triple therapy and dual therapy containing 30 patients each. Treatment groups were well balanced in terms of patient characteristics and baseline parameters (Table 1). The study subjects were divided into subgroups of age, gender, family history, and smoking history to find out in which subgroup the benefit was significant.

\section{SGRQ scores}

The mean change from baseline in SGRQ scores was -21.06 (95\% CI, $-24.92-17.20)$ and -5.89571 (95\% CI, -7.71--4.07) for triple therapy and dual therapy, respectively. Significant differences were observed between initial and final symptoms, activity and impact, and total SGRQ scores of triple therapy patients (Fig. 1). On the other hand, except for symptom component of SGRQ scores, significant differences were observed between initial and final activity, impact, and total SGRQ scores of dual therapy patients (Fig. 2). Mean difference between triple and dual therapy SGRQ scores was -15.13 (95\% CI, -17.15--13.11) which was statistically significant ( $p<0.01$ ) (Fig. 3). Based on the MCID of $>4$ units improvement (decrease) from baseline in SGRQ total scores, the number of responders in triple and dual therapies was 29 (97\%) and 17 (57\%), respectively. The percentage benefit of triple therapy over dual therapy was $97-57 \%=40 \%$ and the number needed to treat to benefit (NNTB) was $1 / 0.4=2.5$. The overall benefit of response versus non-response was statistically significant in favor of triple therapy (risk ratio $=1.69,95 \%$ CI: 1.44-1.99) (Fig. 4).
Table 1: Baseline characteristics of the study population

\begin{tabular}{|c|c|c|c|}
\hline Parameters & $\begin{array}{l}\text { Dual } \\
\text { therapy }\end{array}$ & $\begin{array}{l}\text { Triple } \\
\text { therapy }\end{array}$ & Total \\
\hline Total patients & $30(50 \%)$ & $30(50 \%)$ & $60(100 \%)$ \\
\hline Male (n, \%) & $25(83 \%)$ & $24(80 \%)$ & $49(82 \%)$ \\
\hline Female $(\mathrm{n}, \%)$ & $5(17 \%)$ & $6(20 \%)$ & $11(18 \%)$ \\
\hline Age (mean \pm SD) & $50.5 \pm 12.6$ & $51.5 \pm 12.96$ & $51.03 \pm 12.67$ \\
\hline \multicolumn{4}{|l|}{ Family history } \\
\hline Positive (n, \%) & $8(\%)$ & $9(\%)$ & 17 \\
\hline Negative $(n, \%)$ & $22(\%)$ & $21(\%)$ & 43 \\
\hline \multicolumn{4}{|l|}{ Smoking history } \\
\hline Past smoker (n, \%) & 10 & 9 & 19 \\
\hline oker (n, \%) & 15 & 14 & 29 \\
\hline Nonsmoker (n, \%) & 5 & 7 & 12 \\
\hline \multicolumn{4}{|l|}{ Lung function } \\
\hline FEV1\% predicted & $57.11 \pm 11.71$ & $58.15 \pm 10.30$ & $57.63 \pm 10.95$ \\
\hline FEV1/FVC\% predicted & $54.34 \pm 14.09$ & $54.85 \pm 13.00$ & $56.05 \pm 10.97$ \\
\hline \multicolumn{4}{|l|}{ Quality of life } \\
\hline \multicolumn{4}{|l|}{ SGRQ-c domains } \\
\hline Symptom & $70.06 \pm 15.37$ & $71.32 \pm 8.72$ & $71.68 \pm 9.82$ \\
\hline Activity & $59.88 \pm 13.98$ & $61.46 \pm 12.75$ & $61.49 \pm 11.70$ \\
\hline Impact & $54.89 \pm 11.21$ & $56.33 \pm 7.51$ & $56.41 \pm 7.16$ \\
\hline SGRQ to & $60.48 \pm 4.78$ & $60.27 \pm 6.04$ & $60.38 \pm 5.40$ \\
\hline CAT scores & $25.94 \pm 6.77$ & $23.17 \pm 4.35$ & $24.55 \pm 5.8$ \\
\hline
\end{tabular}

SGRQ: St. George respiratory questionnaire, CAT: Chronic obstructive pulmonary disease assessment test

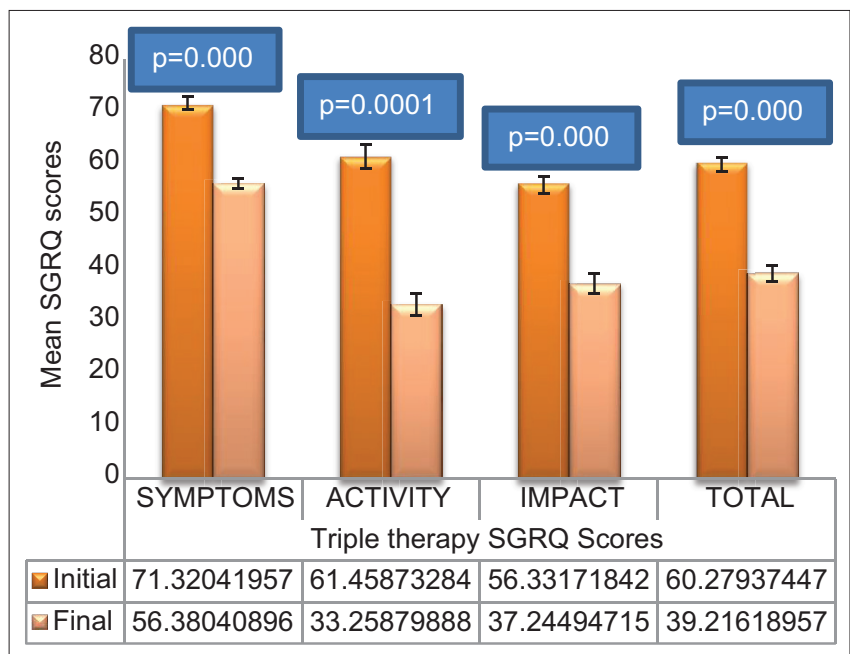

Fig. 1: Initial and final mean St. George respiratory questionnaire scores for triple therapy

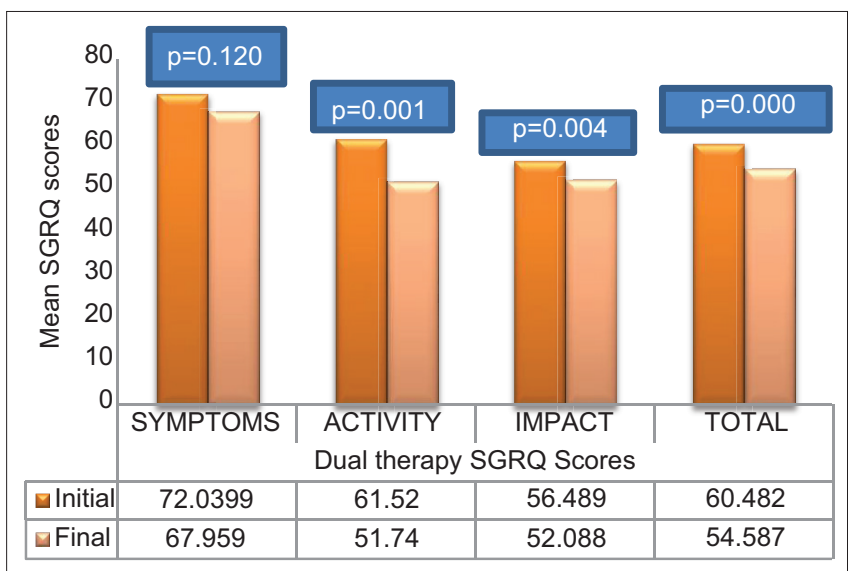

Fig. 2: Initial and final mean St. George respiratory questionnaire scores for dual therapy 


\begin{tabular}{|c|c|c|c|c|c|c|c|c|}
\hline \multirow[b]{2}{*}{ Study or Subgroup } & \multicolumn{2}{|c|}{ Triple therapy } & \multicolumn{3}{|c|}{ Dual therapy } & \multirow{2}{*}{$\begin{array}{l}\text { Mean Difference } \\
\quad \mid \mathrm{V}, \text { Fixed, } 95 \% \mathrm{Cl}\end{array}$} & \multirow{2}{*}{\multicolumn{2}{|c|}{$\begin{array}{l}\text { Mean Difference } \\
\mid \mathrm{V}, \text { Fixed, } 95 \% \mathrm{Cl}\end{array}$}} \\
\hline & Mean & SD To & otal Mean & SD To & & & & \\
\hline Ages 40 years & 25.7416 & 11.8749 & 7.9 .08026 .9 & & 8 & $=16.66[-26.67,66.65)=$ & & \\
\hline Age $>40$ years & 19.6993 & 9.6583 & $23-4.73773 .4$ & & & . $14.90[-19.10,-10.71]$ & 7 & \\
\hline Current smoker & .20 .7172 & 10.1203 & 14.6 .38099 .9 & & 15 & $.14 .34[20.20,8.477]$ & & \\
\hline Female & 18.8696 & 11.7515 & 6.5 .014928 & & 5 & $-13.85[-23.58,4.412]$ & & \\
\hline History negative & .20 .451 & 9.8322 & 21.5 .4474 .6 & 6717 & 22. & $.15 .00[19.64,-10.37]$ & $T$ & \\
\hline History positive & .22 .4915 & 11.9293 & $9 \cdot 7.12845 .5$ & 5133 & 8 & $=15.36[24.04,66.68)$ & & \\
\hline Male & 21.6115 & 10.1544 & $24=6.07195 .2$ & & 25 . & $115.54[20.09,-10.99]$ & 一 & \\
\hline Nonsmoker & 18.4274 & 9.9785 & $7+4.63943 .1$ & & 5 & $: 13.79[-21.68,5.500]$ & & \\
\hline Passt smoker & .23 .6514 & 11.5036 & 9.5 .7965 .7 & 7064 & 10 & $.17 .86[26.16, .9 .55)$ & & \\
\hline Total $\mid 95 \%$ Cll) & & & 120 & & & -15.13[-17.15, 133.11] & 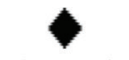 & \\
\hline \multicolumn{5}{|c|}{$\begin{array}{l}\text { Heterogeneity: Chis }=0.80, d f=8(p=1.00) ; p^{2}=0 \% \\
\text { Test tor overal eftect: } z=14.69(p<0.00001)\end{array}$} & & & $\begin{array}{lr}.20 & .10 \\
\text { Favours Triple }\end{array}$ & $\begin{array}{ccc}0 & 10 & 20 \\
\text { s therapy } & \text { Favours Dual therapy }\end{array}$ \\
\hline
\end{tabular}

Fig. 3: Triple therapy versus dual therapy mean change from baseline in St. George respiratory questionnaire scores

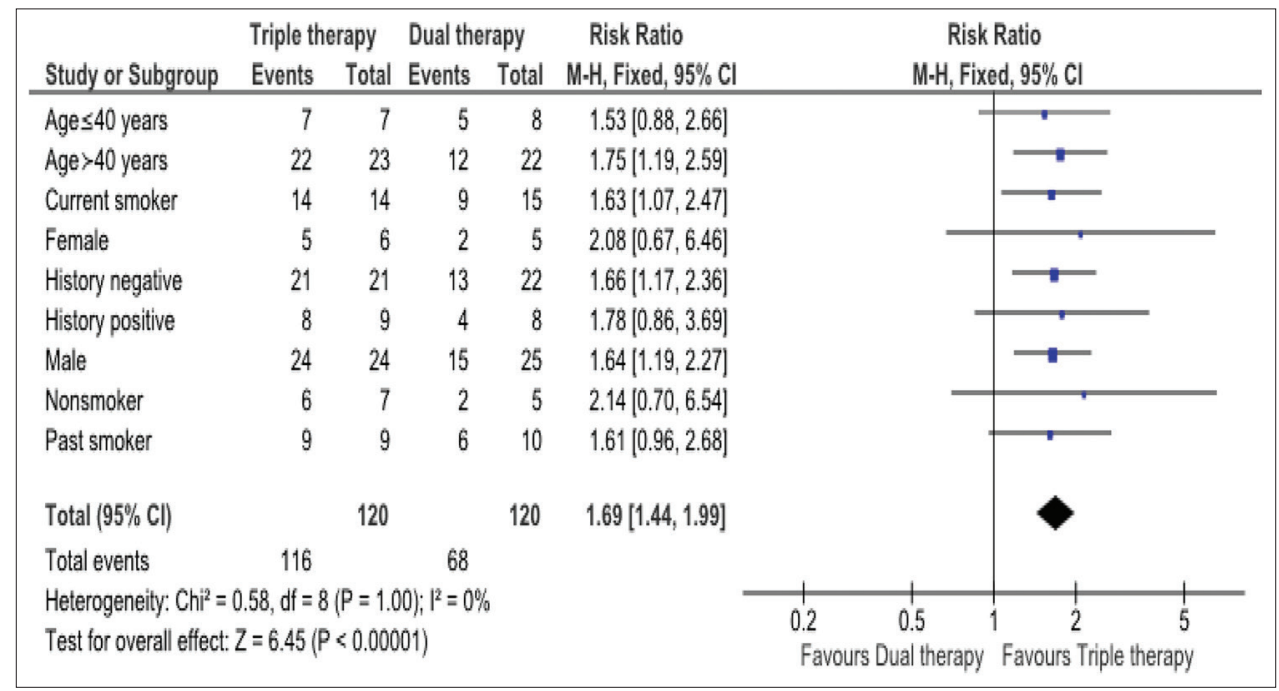

Fig. 4: Triple therapy responders versus dual therapy responders for St. George respiratory questionnaire

\section{Lung function}

The mean change from baseline in FEV1\% predicted was 3.09 (95\% CI, 2.18-4.00) and 1.69 (95\% CI, 1.43-1.97) for triple and dual therapy, respectively. The mean difference between triple and dual therapy FEV1\% predicted values was found to be 1.30 (95\% CI, 0.94-1.67) which was highly significant. Age $>40$ years, male patients, patients with a negative history of COPD and past smokers significantly benefitted from triple therapy. Contrastingly, no significant difference between triple and dual therapies was found in female patients, patients with positive COPD history, age $<40$ years patients, current smokers, and nonsmokers (Fig. 5).

\section{CAT scores}

The mean change from baseline in CAT scores was -2.83 $(95 \%$ CI, -3.73--1.94) and -1.8 (95\% CI, -2.25--1.35) for triple and dual therapy, respectively. The between-treatment mean difference in CAT scores was -1.30 (95\% CI, -1.71--0.89) statistically significant in favor of triple therapy (Fig. 6). Based on the MCID $>2$ for CAT scores, the number of responders in triple therapy and dual therapy was $22(73 \%)$ and 15 (50\%), respectively. Thus, the benefit of triple therapy over dual therapy was 7 (23\%) and the NNTB was 5 . The between-treatment risk ratio for responders versus non-responders was 1.47 (95\% CI, 1.191.18) statistically significant in favor of triple therapy (Fig. 7).

\section{DISCUSSION}

The present study proved that triple therapy was better than dual therapy in terms of lung function and quality of life. This is one of the very few studies where quality of life has been used as a primary outcome parameter for comparing treatment interventions. It is well established that the effectiveness of COPD pharmacological interventions should not be limited to lung function alone $[17,18]$. Except for in the subgroup analysis, triple therapy achieved statistically significant improvements in lung function and quality of life compared to the dual therapy. The statistically nonsignificant results in subgroup analysis may be attributed to the smaller sample size of the study.

Both the therapies showed improvements in lung function and quality of life, but the improvement was more with the triple therapy. This was true with SGRQ mean difference scores where all the subgroups showed statistically significant improvements in favor of triple therapy. Triple therapy achieved $97 \%$ response rates, whereas dual therapy achieved $57 \%$ response rates in terms of SGRQ scores. Patients with age $>40$ years, males, current smokers, and negative family history patients appeared to respond more with triple therapy when SGRQ scores were concerned. Conversely, between-treatment mean difference SGRQ scores showed statistically significant improvements in favor of triple 


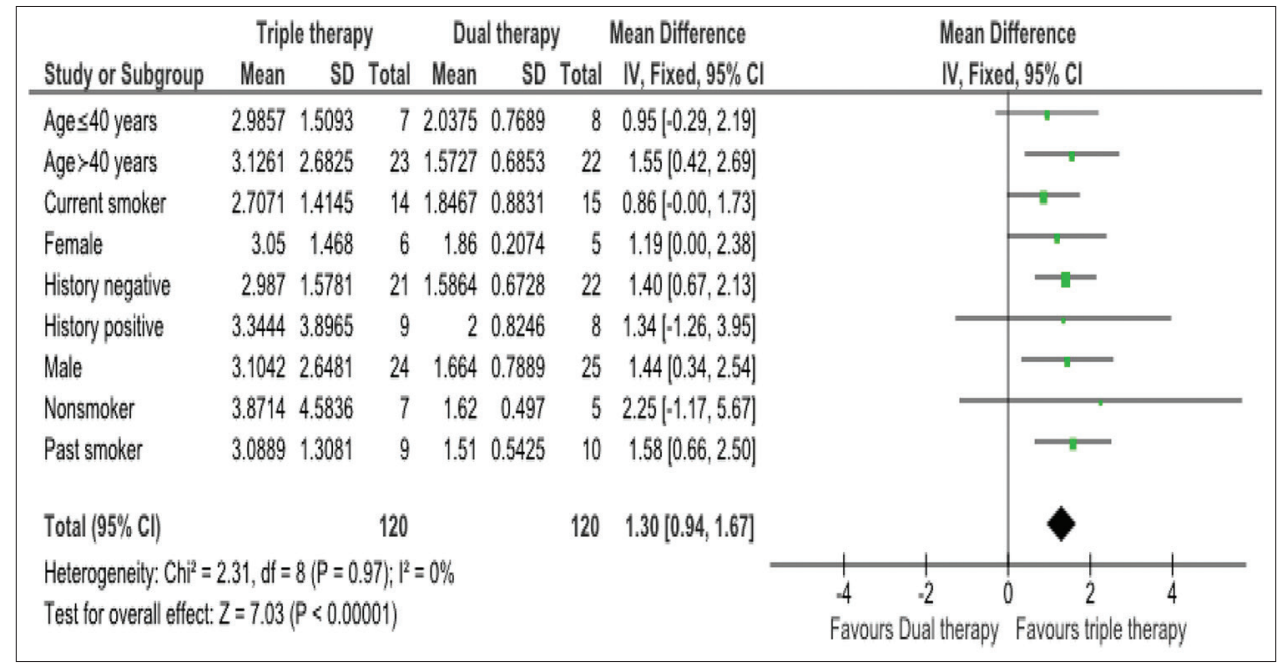

Fig. 5: Triple versus dual therapy mean change from baseline in forced expiratory volume in $1 \mathrm{~s} \%$ predicted values

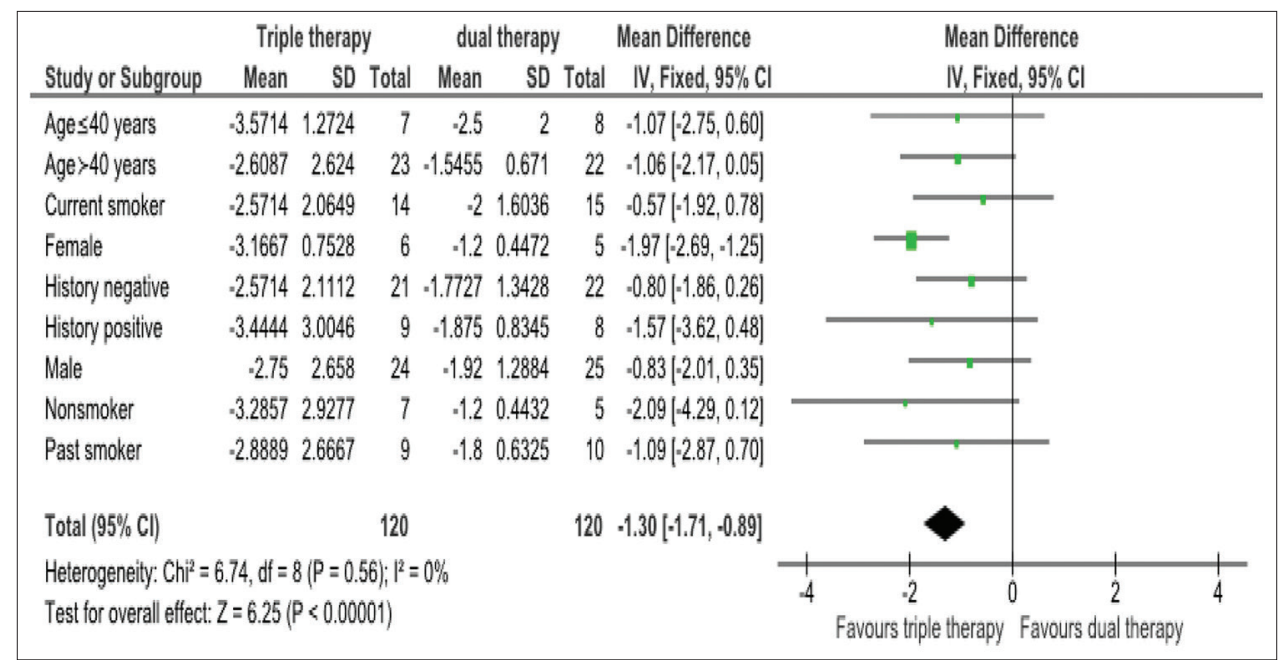

Fig. 6: Triple therapy versus dual therapy mean change from baseline in chronic obstructive pulmonary disease assessment test sores

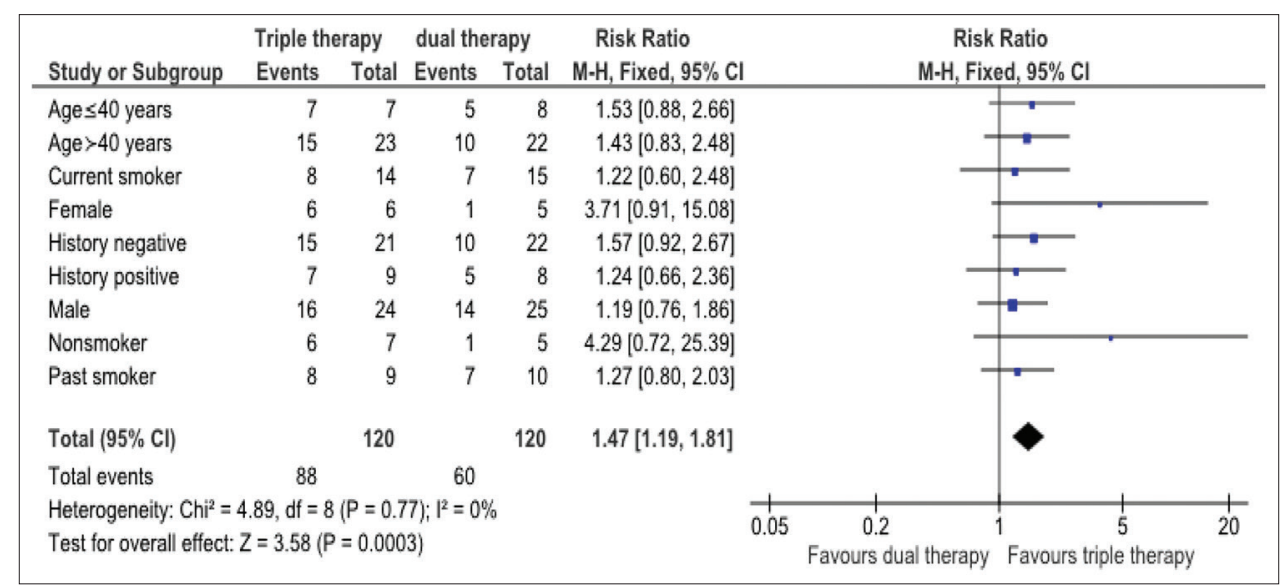

Fig. 7: Triple therapy versus dual therapy chronic obstructive pulmonary disease assessment test responders

therapy with all the subgroups. On the other hand, FEV1\% predicted between-treatment mean difference values present a different picture, where female patients, patients with positive COPD family history and nonsmokers did not seem to benefit much from the triple therapy. These discrepancies in FEV1 and SGRQ scores are also replicated by another study [19], where comparison results of the change in FEV1 and other patient-reported outcomes do not correlate well with each other $[19,20]$. To the best of our knowledge, this is the first study to perform subgroup analysis to compare the effectiveness of triple therapy versus dual therapy.

Both therapies showed improvements from baseline in CAT scores. Triple therapy excelled in all the CAT scores, SGRQ scores, and FEV1\% 
predicted values in terms of between-treatment mean difference and number of responders, but the association between CAT scores, FEV1, and SGRQ scores do not align in the subgroup analysis. Whereas only females had statistically significant mean difference in CAT scores favoring triple therapy, all the subgroups had statistically significant mean difference in SGRQ scores favoring triple therapy. Multiple reasons can be attributed to the discrepancy in SGRQ and CAT score results. First, the SGRQ scale includes a variety of COPD specific health status factors which contribute to the SGRQ scores. CAT scores exclude many of these factors due to item reduction compared to SGRQ scores influencing the output of CAT scores [21]. Likewise, SGRQ has been shown to be more responsive in the case of patients with deteriorated lung function [22] as is the case with the present study patients.

Triple therapy proved to be efficacious than dual therapy in many of the clinical trials, but the magnitude of the effect varies with our study and other studies [23-27]. A recent meta-analysis has shown a betweentreatment mean difference of 0.09 (95\% CI, 0.07-0.12) in absolute FEV1 change from baseline and a between-treatment mean difference -1.67 (95\% CI, -2.02--1.31) in SGRQ score from baseline smaller than what has been reported by our study. Various reasons may be responsible for these differences. First, these trials were longer in duration, have used different doses of drugs, have used different drug combinations of ICS, LABA, and LAMA were majorly conducted as randomized controlled trials, etc. [28].

There are various limitations to this study. The sample size used was very small. The study was conducted as an observational study. An equal number of male and female patients must have been recruited. The study was conducted in Hyderabad only. We did not check the medication adherence of the patients at home and were checked only at follow-ups. We did not account for changes in dosing regimens, different devices used, and different drugs in the LABA, LAMA, and corticosteroid classes. The study does not account for the cost of the therapy which is the major driver for drug use by the patients. Nevertheless, our study was conducted in a real-world setting and thus was able to capture the effectiveness of the drug therapies in the subgroups.

\section{CONCLUSION}

Triple therapy (Formoterol - $6 \mathrm{mcg} /$ Ciclesonide - $200 \mathrm{mcg} /$ Tiotropium $-9 \mathrm{mcg}$ ) can provide improvements in lung function and quality of life over dual therapy (Formoterol $-6 \mathrm{mcg} /$ Tiotropium $-9 \mathrm{mcg}$ ) in patients with moderate to severe COPD. Future studies should focus on which drug combination of triple therapy is more effective and cost-effective than other possible triple therapy drug combinations.

\section{AUTHORS' CONTRIBUTIONS}

Syed Aamir Ali: Concept, statistical analysis, manuscript preparation, manuscript editing, and manuscript review. Remaining authors: Design, literature search, data acquisition, and data analysis.

\section{CONFLICTS OF INTEREST}

The authors declare that they have no conflicts of interest.

\section{REFERENCES}

1. Global Initiative for Chronic Obstructive Lung Disease. Global Strategy for the Diagnosis, Management, and Prevention of Chronic Obstructive Pulmonary Disease; 2005. Available from: http://www.goldcopd.org. [Last accessed on 2019 Jul 15].

2. Miravitlles M, Ferrer M, Pont A, Zalacain R, Alvarez-Sala JL, Masa F, et al. Effect of exacerbations on quality of life in patients with chronic obstructive pulmonary disease: A 2 year follow up study. Thorax 2004;59:387-95.

3. Siler TM, Kerwin E, Singletary K, Brooks J, Church A. Efficacy and safety of umeclidinium added to fluticasone propionate/salmeterol in patients with COPD: Results of two randomized, double-blind studies. COPD 2016;13:1-10

4. Siler TM, Kerwin E, Sousa AR, Donald A, Ali R, Church A. Efficacy and safety of umeclidinium added to fluticasone furoate/vilanterol in chronic obstructive pulmonary disease: Results of two randomized studies. Respir Med 2015;109:1155-63.

5. Pauwels RA, Buist AS, Calverley PM, Jenkins CR, Hurd SS, GOLD Scientific Committee. Global strategy for the diagnosis, management, and prevention of chronic obstructive pulmonary disease. NHLBI/ WHO Global Initiative for Chronic Obstructive Lung Disease (GOLD) Workshop summary. Am J Respir Crit Care Med 2001;163:1256-76.

6. Ferrer M, Alonso J, Morera J, Marrades RM, Khalaf A, Aguar MC, et al. Chronic obstructive pulmonary disease stage and health-related quality of life. The quality of life of chronic obstructive pulmonary disease study group. Ann Intern Med 1997;127:1072-9.

7. Guyatt GH, Berman LB, Townsend M, Pugsley SO, Chambers LW. A measure of quality of life for clinical trials in chronic lung disease. Thorax 1987;42:773-8.

8. Jones PW, Quirk FH, Baveystock CM, Littlejohns P. A self-complete measure of health status for chronic airflow limitation. The St. George's respiratory questionnaire. Am Rev Respir Dis 1992;145:1321-7.

9. Jones P, Harding G, Wiklund I, Berry P, Leidy N. Improving the process and outcome of care in COPD: Development of a standardised assessment tool. Prim Care Respir J 2009;18:208-15.

10. Jones PW, Harding G, Berry P, Wiklund I, Chen WH, Kline Leidy N. Development and first validation of the COPD assessment test. Eur Respir J 2009;34:648-54

11. Cully JA, Graham DP, Stanley MA, Ferguson CJ, Sharafkhaneh A, Souchek J, et al. Quality of life in patients with chronic obstructive pulmonary disease and comorbid anxiety or depression. Psychosomatics 2006;47:312-9.

12. Hu J, Meek P. Health-related quality of life in individuals with chronic obstructive pulmonary disease. Heart Lung 2005;34:415-22.

13. Carrasco Garrido P, de Miguel Díez J, Rejas Gutiérrez J, Centeno AM, Gobartt Vázquez E, Gil de Miguel A, et al. Negative impact of chronic obstructive pulmonary disease on the health-related quality of life of patients. Results of the EPIDEPOC study. Health Qual Life Outcomes 2006; $4: 31$.

14. Balcells E, Gea J, Ferrer J, Serra I, Orozco-Levi M, de Batlle J, et al. Factors affecting the relationship between psychological status and quality of life in COPD patients. Health Qual Life Outcomes 2010;8:108.

15. Cazzola M, MacNee W, Martinez FJ, Rabe KF, Franciosi LG, Barnes PJ, et al. Outcomes for COPD pharmacological trials: From lung function to biomarkers. Eur Respir J 2008;31:416-69.

16. Meguro M, Barley EA, Spencer S, Jones PW. Development and validation of an improved, COPD-specific version of the St. George respiratory questionnaire. Chest 2007;132:456-63.

17. Glaab T, Vogelmeier C, Buhl R. Outcome measures in chronic obstructive pulmonary disease (COPD): Strengths and limitations. Respir Res 2010;11:79.

18. Guyatt GH, Feeny DH, Patrick DL. Measuring health-related quality of life. Ann Intern Med 1993;118:622-9.

19. Vogelmeier CF, Bateman ED, Pallante J, Alagappan VK, D'Andrea P, Chen $\mathrm{H}$, et al. Efficacy and safety of once-daily QVA149 compared with twice-daily salmeterol-fluticasone in patients with chronic obstructive pulmonary disease (ILLUMINATE): A randomised, double-blind, parallel group study. Lancet Respir Med 2013;1:51-60.

20. Westwood M, Bourbeau J, Jones PW, Cerulli A, Capkun-Niggli G, Worthy G. Relationship between FEV1 change and patient-reported outcomes in randomised trials of inhaled bronchodilators for stable COPD: A systematic review. Respir Res 2011;12:40.

21. Morishita-Katsu M, Nishimura K, Taniguchi H, Kimura T, Kondoh Y, Kataoka K, et al. The COPD assessment test and St George's respiratory questionnaire: Are they equivalent in subjects with COPD? Int J Chron Obstruct Pulmon Dis 2016;11:1543-51.

22. Sciriha A, Lungaro-Mifsud S, Scerri J, Magro R, Camilleri L, Montefort S. Health status of COPD patients undergoing pulmonary rehabilitation: A comparative responsiveness of the CAT and SGRQ. Chron Respir Dis 2017; 14:352-9.

23. Lipson DA, Barnhart F, Brealey N, Brooks J, Criner GJ, Day NC, et al. Once-daily single-inhaler triple versus dual therapy in patients with COPD. N Engl J Med 2018;378:1671-80.

24. Papi A, Vestbo J, Fabbri L, Corradi M, Prunier H, Cohuet G, et al. Extrafine inhaled triple therapy versus dual bronchodilator therapy in chronic obstructive pulmonary disease (TRIBUTE): A double-blind, parallel group, randomised controlled trial. Lancet 2018;391:1076-84.

25. Lipson DA, Barnacle H, Birk R, Brealey N, Locantore N, Lomas DA, et al. FULFIL trial: Once-daily triple therapy for patients with chronic obstructive pulmonary disease. Am J Respir Crit Care Med 
2017; 196:438-46

26. Singh D, Papi A, Corradi M, Pavlišová I, Montagna I, Francisco C, et al. Single inhaler triple therapy versus inhaled corticosteroid plus long-acting 32 -agonist therapy for chronic obstructive pulmonary disease (TRILOGY): A double-blind, parallel group, randomised controlled trial. Lancet 2016;388:963-73.

27. Khan PA, Sujala A, Nousheen BS, Fatima AF, Ala HT,
Reddy AP. A comparative evaluation of the efficacy of triple drug therapy with dual drug therapy in COPD patients. Int J Pharm Pharm Sci 2018;10:105-9.

28. Zayed Y, Barbarawi M, Kheiri B, Haykal T, Chahine A, Rashdan L, et al. Triple versus dual inhaler therapy in moderate-to-severe COPD: A systematic review and meta-analysis of randomized controlled trials. Clin Respir J 2019;13:413-28. 